\title{
Correction
}

\section{'Cephalosporin allergy' label is misleading [Correction]}

Aust Prescr 2018;41:205

https://doi.org/10.18773/austprescr.2018.061

The article by Carlo L Yuson et al. on the 'cephalosporin allergy' label (Aust Prescr 2018;41:37-41) has been amended.

The general structure of cephalosporins, as depicted in Fig. 1, was corrected, as were several of the R1 side chain structures of cephalosporins and penicillins shown in the Table.

The original article has now been updated.

\section{EDITORIAL OFFICE}

For general correspondence such as Letters to the Editor, contact the Editor.

Postal The Editor

Australian Prescriber

Level 5, 15 Moore Street

Canberra, ACT 2600

Telephone +61282178700

Email_info@australianprescriber.com

Website nps.org.au/australianprescriber

Twitter@AustPrescriber

\section{SUBSCRIPTIONS}

Australian Prescriber is published every two months online. All content is accessible free of charge in full text at nps.org.au/ australianprescriber. New drugs are published between issues as they become available.

An email alert can be sent to you when Australian Prescriber publishes new material. Subscribe or update your details at nps.org.au/australianprescriber

For back issues, and copies of the Anaphylaxis wallchart and Switching-antidepressants poster, email info@australianprescriber.com
ANSWERS

TO SELF-TEST QUESTIONS

1 False 2 True
(C) 2018 NPS MedicineWise ABN 61082034393

NPS MedicineWise Disclaimer Reasonable care is taken to provide accurate information at the time of creation. This information is not intended as a substitute for medical advice and should not be exclusively relied on to

manage or diagnose a medical condition. NPS MedicineWise disclaims all liability (including for negligence) for any loss, damage or injury resulting from reliance on or use of this nformation. 